\title{
Developing Higher Order Thinking Skills: Towards a Rethinking of EFL Coursebooks in Moroccan High Schools
}

\author{
Isam Mrah \\ Mohammed First University \\ Faculty of Letters and Human Sciences, Oujda, Morocco \\ e-mail:mrahissam@gmail.com
}

\begin{abstract}
The ever-growing realm of education underlines the need for a reconsideration of learning materials. The present study aimed to investigate the extent to which EFL textbooks in Morocco help learners build skills in accordance with the twenty first century learning expectations. It attempted to assess the effectiveness of Ticket to English textbook series in terms of how well they foster critical thinking and problem solving among learners. The study adopted content analysis as the primary research method for data analysis and interpretation. The analysis was undertaken to define the types and levels of questions addressed in reading comprehension tasks and to examine instances of higher order thinking skills. The case study evaluated the questions in the light of the Bloom's Revisited Taxonomy of learning objectives. Results from the content analysis of questions show that most of the questions targeted the three lower-level categories of the taxonomy. The results obtained testify that the examined textbooks do not effectively enable learners to be autonomous lifelong critical thinkers, hence the need for a reconsideration of EFL textbooks in Moroccan high schools. The paper eventually suggests some ways in which these skills could be promoted effectively in future textbooks with the aim of empowering students to thrive in an evolving world.
\end{abstract}

Keywords: bloom's taxonomy, textbook evaluation, critical thinking, reading comprehension, higher order thinking skills 


\section{INTRODUCTION}

In the ever growing and evolving world of information communication technology, traditional teaching practices are faced with myriad challenges that exceed their ability to cope with the demands of the twenty first century skills. Today, more than any time in recent history, it becomes imperative for educational systems to develop a new set of skills that keep pace with the technological dependence and the demands of global citizens typical of this century. In developing countries like Morocco, teachers extensively depend on textbooks to provide a stepby-step guide on what to teach and how to teach. Despite the technological advances of modern society, textbooks will definitely remain central to language teaching and learning in that they provide useful resources for both learners and teachers and help ensure that the official guidelines are being adhered to (Richards, 2001). With this in mind, textbooks must be qualified in terms of their roles in the educational environment.

In the age of information technology, individuals are constantly receiving a great deal of information from various sources in a way that makes it compelling to process online content through critical eyes. The same holds true for language learners who are exposed to a wide range of texts which necessitates them tapping into their thinking skills and engaging in a complex interaction between the text, reader background, and reading strategies. A plethora of research on cognitive science has investigation the interrelation between reading compression ability and reading strategies. Few studies, however, have probed the role of higher order thinking in reading comprehension.

Developing critical thinking skills and critical thinking disposition among high school students has become a pressing need to enhance students' employability in the fast-changing workplace. Students need to truly value their ability to solve problems throughout their lives in terms of obtaining, understanding, analyzing, and sharing information.

To this end, educational policy makers, teacher trainers, school inspectors, and textbook designers need to join efforts to provide teachers with the most up-to-date practices, materials, and guidance on how to effectively and explicitly teach skills to better respond to the changing realities of the twenty first century

\subsection{Statement of the Problem}

Textbooks are basic components of English language teaching (ELT) and are the most extensively used instructional materials in schools at present. A plethora of research has delved into the relationship between reading comprehension and the use of reading strategies. However, a few studies have examined the impact of critical thinking on reading comprehension among second language learners.

Moroccan public schools are by no means an exception. They are still heavily dominated by traditional based approaches to the teaching of reading comprehension where the primacy of rote learning is clearly manifested. Developing students' evaluative and reflective skills are not given due consideration. As the researcher is a high school English language teacher, he noticed students struggling hard to answer reading comprehension questions at the levels of higher order thinking skills 
(HOTS). The researcher presupposed that this deficiency is attributed to the lack of reading comprehension activities that fail to help learners practice HOTS. The high school English classroom is an optimal environment in which to explicitly teach and practice critical thinking with the aim of developing life-long habits of learning (Hove, 2011).

The dominant tendency in Moroccan contemporary schools has been to equate learning with short-term proficiency of fact recall. Many students tend to adopt a superficial and impressionistic interpretation while reading texts. Accordingly, they fail to accurately capture the meaning of the texts they read (Paul \& Elder, 2009). Most of the blame is placed on teachers failing to explicitly teach the skills students require to decode texts. Another important consideration is that high school courses are designed in a way that allow students to pass without ever being required to think deeply.

Against this background, the present study draws the attention of EFL practitioners to the increasing role textbooks play in enhancing higher order thinking among learners. It is built on the premise that the Moroccan EFL textbooks need to be aligned with the twenty first century skills requirements. Accordingly, there is an urgent need to modify existing teaching materials and offer alternative activities where learners can become reflective and self-directed. In order for high school students to be capable enough to compete for employment in a global economy, they ought to be encouraged and trained to think critically and strategically. A rigorous English curriculum based on a structured, explicit, and scaffolded approach to teaching critical thinking skills will better prepare high school students for college and employment (Hove, 2011).

\subsection{Significance of the Study}

There is a plethora of literature and empirical studies on the significance of evaluating materials used for teaching English. Materials evaluation is an educational requirement which shows how a textbook can be improved or justified (Alamri, 2008). The use of appropriate teaching materials and textbooks along with effective teaching methodologies are central for attaining the goals set in the curriculum. Despite the increasing use of modern information technology in education, teaching materials, particularly coursebooks, remain at the core of any language learning program. One of their primary functions is to serve as progress indicators for both learners and teachers (Roberts, 1996).

With minor exceptions, there is scant literature on EFL textbook evaluation in Morocco (Bouzid, 2016a, 2016b; Laabidi, 2016). Most studies on textbook evaluation have extensively focused on how the four skills of language learning are presented and practiced. Other studies have examined cultural processes represented in EFL textbooks and which are arguably conducive to the making and reshaping of identities (Elboubekri, 2013). To extend the scope of research on EFL textbook evaluation, this study purports to deepen our knowledge of scaffolding strategies used to support lifelong learning.

This study has both theoretical and practical contributions. First, it contributes to the existing literature on textbook evaluation and the characteristics of effective 
teaching materials. Second, the study also aimed to provide empirical findings based on the case study which may serve as a possible guide for future textbook evaluations. This evaluation would also benefit classroom instructors on areas which need improvement or which require the use of supplementary materials.

\subsection{Purpose of the Study}

The purpose of this study was to evaluate the effectiveness of Ticket to English, a series of textbooks designed for eleventh and twelfth grade Moroccan students, in terms of how well they foster critical thinking and problem solving among learners. The primary motivation for undertaking this study lies in the fact that the content of textbooks has a significant impact on students' learning and cognitive achievement. By effectively evaluating the content of textbooks, it is possible to determine whether the educational needs of students are adequately being met. As explained Weir and Roberts (1994, p.11), the evaluation of teaching materials serves two major purposes: (a) it can inform theoretical disputes about directions to be followed in language teaching or in teacher education and (b) indicate the suitability of particular approaches or techniques under given conditions.

Textbook evaluation provides a reference for subsequent revisions and improvement of certain aspects of the examined textbooks. This is significant given the centrality of these books for high school students who are about to undertake higher studies. As such, the purpose of this study was to identify the areas of weaknesses and prescribe remedial measures to develop English language curricula. This paper is an attempt to convince language teachers to take a critical approach to textbook evaluation to make language teaching more efficient. It also suggests ways in which future textbooks could improve their content by including more activities targeting the teaching of HOTS.

\subsection{Research Question and Hypothesis}

The research questions driving this study were:

1. To what extent do Moroccan textbooks of English (Ticket to English) and particularly reading comprehension activities promote higher order thinking skills?

2. To what extent do the reading activities promote analysis, synthesis, and evaluation skills?

3. What type of teaching/learning activities would benefit most students in terms of developing their HOTS?

The working hypotheses guiding this research can be summarized as follows:

1. The examined textbooks do not provide a gradual progression from lower to higher order thinking skills.

2. The examined textbooks do not provide enough learning materials and activities that help students become higher level thinkers and learners. 


\subsection{Limitations of the Study}

One of the limitations of this study is its reliance on a single sample coursebook for data analysis. There is a need to expand the scope of analysis to other related coursebooks used in Moroccan public schools to gather more data and draw more conclusive results. Having said that, findings of the study cannot be generalized to all public schools which use different textbooks. Another limitation is the need to administer a questionnaire to investigate Moroccan teachers' and students' perspectives regarding the place of HOTS in EFL textbooks.

\section{LITERATURE REVIEW AND THEORITICAL FRAMEWORK}

The purpose of this section is to review literature related to textbook evaluation, bloom's taxonomy, reading comprehension, and higher order thinking skills.

\subsection{Materials Evaluation}

This study rests on the assumption that textbook evaluation is of critical importance to the teaching-learning process. Several studies have been undertaken on the role of textbook evaluation in language teaching and learning (Grosskopf, 1981; Williams, 1983; Kearsey \&Turner , 1999). Other studies focused on developing criteria for materials evaluation and selection (Ericksen \& Pena-Shaff (2006).

Materials evaluation is a procedure commonly used in the field of applied linguistics. Lynch (1996) refers to evaluation as the systematic attempt to gather information in order to make judgments or decisions (p. 2). Harmer (2001) draws a distinction between evaluation and assessment. Coursebook assessment is "an outof-class judgment as to how well a new book will perform in class"(Harmer, 2001, p. 301). Coursebook evaluation, on the other hand, is a judgment on how well a book has performed in fact(Harmer, 2001, p. 301).

Textbook evaluation is a reflective practice intended to refine the quality of ELT textbooks. It aims to provide opportunities for teachers to reflect upon the teaching material in terms of its authenticity, appropriacy and effectiveness along with considering innovative future directions for their teaching practices. It is a systematic, reflective, and longitudinal practice that seeks to uncover the underlying structure and content of a textbook (Tomlinson, 2001).

Materials evaluation is a procedure through which teachers, supervisor, administrators, and materials developers can "make judgments about the effect of the materials on the people using them" (Tomlinson, 2001, p. 15). According to Cunningsworth (1995), one of the main reasons for materials evaluation is to identify particular strengths and weaknesses in coursebooks already in use, so that optimum use can be made of their strong points, whilst their weaker areas can be strengthened through adoption or by substituting materials from other books (p. 14). Evaluation, which is the process of collecting, analyzing and interpreting information, enables educators to make informed decisions about educational programs (Genesee, 2001). 
Within the area of ELT textbook evaluation, a handful of research studies (Byrd, 2001; Harmer, 1991; Tomlinson, 2005) have embarked on the development of evaluation schemes, particularly checklists, to assess the pedagogical effectiveness of a textbook (Mishan \& Tomlinson, 2017). Ansari and Babaii (2002) devised a framework for textbook evaluation consisting of four parts: approach, content presentation, physical make- up, and administrative concerns. The evaluation of the approach adopted takes into account the nature of language, learning, and how theory can be applied. Content evaluation is most concerned with purposes, selection and rationale of materials, and syllabus satisfaction. As for physical make-up, the focus is on the size, layout, durability, quality of editing, and appropriate title. Finally, evaluation of the administrative concerns includes macrostate policies, and appropriateness for local situation (Behjat, 2013).

According to Sheldon (1988), the textbook remains an essential element in every classroom activity as it represents the visible heart of any ELT program. Textbooks, however, can often lead to educational failure in the absence of systematic criteria for assessing textbooks (Sheldon,1988). In short, for textbooks to achieve the desired learning outcomes effectively, their content, approach and methodology must be effectively evaluated. This practice is essential in improving the quality of the teaching learning process as it allows for refining the quality of the textbooks and materials used as teaching-learning tools in the classroom (Sheldon, 1988).

Research maintains that textbook evaluation is a reflective practice that has the potential of boosting the quality of ELT textbook. Textbook evaluation has become an established practice in the field of English language teaching considering the increasing trend of globalization in today's society and the educational value of critical thinking in the development of higher cognitive functions and the formation of reflective learners.

In his article entitled Fundamental criteria for effective textbook evaluation, Laabidi (2016) investigated Moroccan teachers' attitudes towards EFL textbook Visa to the World designed for common core high school students. The study set out to explore the effectiveness of the language teaching methods and learning activities adopted in the textbook. The most important finding is that the examined textbook does not seem to follow a logical sequence from simple to complex regarding the tasks and activities. The general implication drawn from this study is the necessity to carry out a detailed needs analysis before designing a textbook.

In recently published study on the integration of the 21 st century skills in Moroccan ELT Textbooks, Bouzid (2016) explored a broad array of learning activities used to foster higher order thinking skills and eventually recommended a set of tasks that would effectively promote these skills in future textbooks. Using both qualitative and quantitative content analysis, the study found that the examined textbooks provide a small range of activities that stimulate young learners to think creatively and develop career and life-skills. Another study conducted by the same researcher examined the religious content of Moroccan ELT textbooks towards a better understanding of the representation of religion as a cultural perspective in a series of textbooks. Based on findings obtained from a mixed method design and a 
mixed content analysis, the study revealed that the examined textbooks do not sensitize learners to critical issues of diversity, tolerance, and peaceful coexistence among different religions (Bouzid, 2016).

In a more recent study on the use of commercial textbooks in higher education, Subekti analyzed and evaluated a textbook designed for English 1 course to provide insights on the core elements of curriculum development. The key finding of the study is that the examined textbook does not assist learners to attain all of the learning aims of English 1 course. As such, it results in a disparity of learners' achievements across different classes (Subekti, 2017).

Despite the apparent significance of material evaluation, there seems to be relatively few empirical research studies compared with the theoretical ones. Correspondingly, the number of textbook evaluation studies undertaken in Morocco are still relatively scarce.

\subsection{Bloom's Revisited Taxonomy}

Bloom's Taxonomy provides a useful theoretical framework for designing sequential educational objectives with the aim of enabling learners to move from lower knowledge levels to higher level thinking skills. The taxonomy identified six levels of learning: a) knowledge which includes recalling previously learned material and grasping its meaning; b) comprehension which involves constructing meaning by making connections between the text and the reader's prior knowledge; c) application defined as the use of previously learned information in new situations in order to solve problems; d) analysis which refers to the ability of learners to break down information into component parts to make valid generalizations; e) synthesis entails the ability to conceive new or original concepts; and f) evaluation intended to develop the ability to judge the quality and credibility of information (Anderson, 2001).

As educators have become increasingly interested in the accurate assessment of student learning, the original taxonomy has been subject to revision and amendment. Anderson and Krathwohl (2001) revisited Bloom's original taxonomy and changed the categories from nouns to verbs by incorporating both the kind of knowledge to be learned - knowledge dimension - and the process used to learncognitive process- making it possible for the instructional designer to align learning objectives to assessment techniques. The two dimensions can be used to help write clear, focused objectives (Cruz, 2003). The learning objectives for an entire unit can be entered into the taxonomy table to ensure that all levels of the cognitive process are being utilized and that students are introduced to different types of knowledge.

The revised taxonomy includes the following cognitive functions: (a) remembering which involves the ability to recognize and recall information from memory; (b) understanding which is critical to the construction of meaning from various types of functions; (c) applying includes the use of information in another familiar situation through executing or implementing; (d) analyzing which refers to the ability to break information into parts to explore understandings and relationships; (e) evaluating which enable students to make judgments and decisions about the value of ideas or materials based on in-depth reflection, criticism and 
assessment; and (f) creating which involves the use of higher order thinking skills to generate new ideas and information using what previously has been learned and combine elements to form a coherent whole(Anderson, 2001).

Bloom's Revisited Taxonomy ensures alignment between standards and assessments to transform English language teaching from traditional teachercentered method to student-centered model purported to help learners solve problems, evaluate, synthesize and create to maximize the internalization of learning. The categories were ordered from simple to complex and from concrete to abstract. The Taxonomy is a cumulative hierarchy of thinking levels, meaning that a mastery of each simpler category is precondition to mastery of the next more complex one (Krathwohl, 2002).

The levels increase in complexity from lower-order knowledge skills (Knowledge, comprehension and application) to higher-order knowledge skills ( analysis, evaluation and creating).The lower levels are associated with convergent thinking while the higher levels typically correspond to divergent thinking. Convergent thinking is common in traditional instruction methods which promote the transition of information particularly factual knowledge to students who are supposed to receive, collect and remember the information communicated to them. This type of instruction uses formal testing as an essential component of assessment for which there is only one right answer. Divergent thinking, on the other hand, is a thought process based on higher critical thinking skills that allows the student to mobilize various resources such as information technologies to generate possible answers to a question. This type of instruction is aimed to enable students to become actively involved in their own learning. A variety of assessment methods can be designed such as student self evaluations and collaborative observations to measure whether students have attained the desired learning outcomes and skills. Bloom's Revisited Taxonomy of learning objectives can be applied to evaluate the types of reading comprehension activities in Ticket to English and gauge its effectiveness in enhancing HOTS among learners. To this end, a coding scheme was designed on the basis of the revisited taxonomy.

\subsection{Higher order Thinking Skills}

Often called critical or strategic thinking, higher order thinking includes the ability to use information to solve problems, analyze arguments, negotiate issues or make predictions (Wenglinsky, 2002). It also involves the ability to examine assumptions and values, evaluate evidence, and assess conclusions (Petress, 2005). This type of thinking goes beyond basic memorization and recognition of facts to manipulating information, allowing students to solve problems, gain understanding and discover new meaning (Tomei, 2005).

According to McDavitt (1993, p. 20),HOTS include analysis, synthesis, and evaluation and require mastery of previous levels, such as applyin routine rules to familiar or novel problems. Correspondingly, McDade (1995, p. 10) defines HOTS as the intellectually disciplined process of actively and skillfully conceptualizing, applying, analyzing, synthesizing, and/ or evaluating information gathered from, or 
generated by observation, experience, reflection, reasoning, or communication as a rubric to belief and action.

Higher-order questions (HOQs) are those that require students to manipulate information by using higher levels of thinking (analysis, synthesis and evaluation). Lower-order questions (LOQs) are those that require the use of lower levels of thinking (knowledge, comprehension and application) (Chen, 2016). HOQs can be referred to as high-cognitive, divergent, or referential questions while LOQs can be referred to as low-cognitive, convergent, or display questions. Lower-order thinking (LOT) is a precondition for enhancing higher-order thinking. Bloom (1956) suggested that a person cannot apply value or judgment without knowing the facts, understanding the facts, being capable of applying the facts, and being able to disassemble and reassemble the facts (cited in Chen, 2016, p. 218).

HOTS require high intellectual processes and cultivation of one's mind and thoughts, enabling the individual to become an active learner rather than a passive recipient of information, question the taken-for-granted assumptions, and take responsibility for seeking evidence and analyzing their knowledge (Wright, 2002). This involves the ability to (a) define and clarify problems, issues, conclusions, reasons, and assumptions; (b) judge the credibility, relevance and consistency of information; (c) and infer or solve problems as well as drawing reasonable conclusions (Jones, 1989).

There is a growing need to help students know how to learn and how to think clearly (Halpern, 1998, p. 450) 2 and make purposeful judgments about what to believe or what to do (Facione, Sanchez \& Gainen, 1995, p. 3). Accordingly, school curricula need to be reexamined as they tend to promote systematic, error-free learning - correct answers, assimilation of facts, and teacher's assessment.

Like any other skill, developing proficiency in CT requires a scaffolded approach. Cognitive scientists maintain that HOTS are only possible when one has relevant knowledge (Senechal, 2010). In other words, the ability to think critically involves a progressive mastery of a hierarchy of skills, and to reach advanced levels of critical thought, students must first develop basic thinking skills (Senechal, 2010). Mendelmen (2007) notes that CT instruction involves a gradual progression from the superficial to the increasingly complex (p. 300). Correspondingly, Paul and Elder (2008) maintain that educators must structure lessons to enable increasing levels of challenge.

The reviewed literature on HOTS testifies to the need to incorporate skills that can meet the needs of the 21st century learners in the English curricula designed for foreign language learners. Students' success in today's world rests upon their ability to adapt to new situations through self-reflection and the need for being innovative and creative in their attempt to solve real life problems. Aside from enhancing learners' communication skills, foreign language classes should include possibilities for learners to develop skills necessary to identify and retrieve relevant information, organize it and evaluate its usefulness and quality. 


\subsection{Reading comprehension and higher order thinking skills.}

Reading comprehension is an interactive skill in which the reader interacts with the text, building on experience and previous knowledge and mobilizing cognitive and meta cognitive strategies to get the intended meaning. Reading is a complex process that requires readers to recall, retrieve and reflect on their prior experiences or memories to construct meanings of the text (Tung \& Ying, 2009). The process of reading comprehension involves actively constructing meaning among the parts of the text and personal experience. The text itself is a blueprint for meaning (McNeil, 1984 cited in Arena, 2013,p. 94). Sheorey and Mokhtari (2001) asserted that "reading is not a linear process but one in which readers constantly form hypotheses, test predictions, and use their knowledge of the world and of the language to construct meaning" (p. 432). Reading comprehension is an active negotiation between the reader and the text, a process which involves top-down and bottom-up strategies that take into account a whole range of reader and text attributes (Woolley, 2001).

Reading texts provide readers with a variety of real-world scenarios to help them construct meanings from multiple perspectives and contest ideas. The reasoning behind exposing readers to multiple points of view is to prompt them to think and rethink their own ideas and actions. This is largely believed to help students gradually achieve self-direction and develop the disposition to become open-minded, self-confident, prudent and truth-seekers. (Facione, 1992). Research indicates that good readers tend to decode words automatically, and more importantly, construct meaning and bring in their prior knowledge to interact with the text (Adams, 1990).

Reading comprehension texts are important assets to train learners to practice levels of cognitive skills which are an integral part of the whole learning process. Reading comprehension is particularly congenial to the development of higher order thinking. The cognitive process of reading is contingent upon HOTS. Readers are called on to activate existing schemata and construct new ones by engaging in reflective thinking (Norris \& Phillips, 1987). Contrary to the traditional view that calls for students to reproduce statements being read in a comprehension text, schema theory proposes an interactive approach that views teaching reading comprehension as a process. To this end, students are introduced to a range of techniques for text processing, including making inferences, activating prior knowledge, and using critical thinking (McNeil,1992; Aloqaili, 2005; Orbea \& Villabeitia, 2010).

When confronted with a challenging text, metacognition, which is the ability to think about one's thinking, allows young thinkers to efficiently and accurately assess their repertoire of strategies with the aim of selecting the best strategy for a given situation (Bruning et.al., 2004). As explained by Lombard, (2008, p. 1031), metacognition " allows - a critical thinker [to] be able to monitor and evaluate a problem solving process, make conclusions, react effectively to new task and situations and process information effectively."

In the process of reading, readers learn how to extract meaning from text and reconstruct it by integrating information from the text into their background 
knowledge to make assumptions and draw conclusions. This is rather a complex mental process whereby the reader decodes language to thought. Efficient readers seek direct path to meaning, use strategies for eliminating uncertainty, and draw on prior conceptual and linguistic competence (Carrell, et all, 1988). It is therefore possible to conceptualize the reader as an "active information processor."

Improving the quality of student thinking is an explicit priority of current educational reform efforts. Curriculum and educational programs are responsible for enhancing learners' abilities and thinking skills. Students should be trained how to read to become effective readers (Marier, 2000). It is important to learn how to draw conclusions from what is implied in the text by taking pieces of information and synthesizing them into a meaningful and coherent whole. It can be concluded that there is a close connection between reading comprehension and higher order thinking.

Many teachers take it for granted that young learners will develop higher order thinking and critical reading skills automatically as they grow older and become more knowledgeable through reading in school. However, this widely held view has been contested by various ELT researchers including Stauffer (1977) who is of the opinion that higher order thinking must and can be taught to students. Schools are accountable for developing citizens who will have the ability to read and think critically.

Within the same line of thought, other educational experts stress the need for developing students' critical thinking in the early grades (Hickey, 1988; McMillan \&Gentile, 1988). Thistlethwaite (1990), for instance, goes further to note that "focusing on critical reading should not wait until presumably lower level reading skills have been mastered" (p.586).The above mentioned quote implies the importance of providing guidance to achieve active and critical reading comprehension of difficult texts. Teachers need to enable students to critically examine any text using key strategies for close reading (Bean \& Ericson, 1989). School instruction should guide students to gradually expand their range of competence, and adequately prepare students to take charge of their own learning.

\section{RESEARCH METHODS}

This exploratory research adopted a content analysis approach (Krippendorff, 2013) to evaluate the content of Moroccan ELT textbooks currently used in teaching the eleventh and twelfth grades students in public schools, namely Ticket to English 1 and Ticket to English 2 (Hammani, Ahssen \& Tansaoui, 2007). The textbooks were analyzed to examine the extent to which they present activities that can develop learners' HOTS. Hsieh and Shannon (2005, p.1278) define content analysis(CA) as " a research method for the subjective interpretation of the content of text data through the systematic classification process of coding and identifying themes or patterns" (cited in Kennedy et al., p. 2016). CA is an effective research method employed to statistically manipulate large quantities of textual information and systematically identify characteristics or properties (Patton, 2002).

The researcher built a checklist based on Bloom's revised taxonomy of learning objectives as a criterion for the evaluation process. The quantitative analysis was 
conducted through scanning reading texts and counting the number of activities to measure the frequency of HOTS. The purpose of the quantitative analysis was to identify whether the number of these activities is adequate for promoting these skills. To this end, a systematic random sample was utilized to ensure a fair representation of the data and avoid possible bias in the selection. The total number of the selected texts is 5 for each grade level knowing that the overall number of reading texts that students are required to cover is 10 . A number was assigned to every reading text for each grade level followed by a choice of the third number from that data. To identify the needed sample size, the total number of the texts (10) for each grade level was divided into the sample size (3) to obtain the sampling fraction (3). The sampling fraction is then used as the constant difference between subjects. As a final step, the frequencies and percentages of occurrences of learning objectives were calculated.

\section{FINDINGS}

The purpose of this study was to evaluate the quality of the eleventh and twelfth grade English language textbooks Ticket to English. The data were subjected to analysis through descriptive statistics. The findings revealed that the bulk of reading comprehension activities analyzed place a considerable emphasis on lower order thinking skills, namely understanding (40,5\%), remembering (15\%), and applying (14\%) while higher order thinking skills such as evaluating (18\%) and analyzing $(11,5 \%$ )are not being fully developed (Table 1$)$. The examined textbooks do not include activities that target the highest level of thinking which is creating. Most of the reading tasks examined tend to focus on what happened instead of questioning why or how it happened. As such, students' mental processes operate according to Bloom's bottom two low-order thinking skills-knowledge and comprehension - rather than trying to explain and reflect on beliefs and actions.

\section{Table 1}

Occurrences and Percentages of Bloom's New Taxonomy of Cognitive Domain

\begin{tabular}{llllll}
\hline & \multicolumn{2}{l}{ Ticket to English 1 } & \multicolumn{2}{l}{ Ticket to English 2 } & Total (\%) \\
\cline { 2 - 6 } $\begin{array}{l}\text { Cognitive } \\
\text { Domain }\end{array}$ & Occurrences & Percentage & Occurrences & Percentage \\
\hline Lower level & & & & & \\
& & $19 \%$ & 3 & $13 \%$ & $15 \%$ \\
Remembering & 3 & $37 \%$ & 10 & $44 \%$ & $40,5 \%$ \\
$\begin{array}{l}\text { Understanding } \\
\text { Applying }\end{array}$ & 6 & $19 \%$ & 2 & $9 \%$ & $14 \%$ \\
Higher-level & 3 & & & & \\
& 1 & $6 \%$ & 4 & $17 \%$ & $11,5 \%$ \\
$\begin{array}{l}\text { Analyzing } \\
\text { Evaluating }\end{array}$ & 3 & $19 \%$ & 4 & $17 \%$ & $18 \%$ \\
Creating & 0 & $0 \%$ & 0 & $0 \%$ & $0 \%$ \\
\hline
\end{tabular}


Both Ticket To English 1 and 2 show almost similar results in terms of the cognitive domains being developed (Figure 1). The textbooks draw extensively on literal and inferential comprehension at the expense of evaluative comprehension and creation.

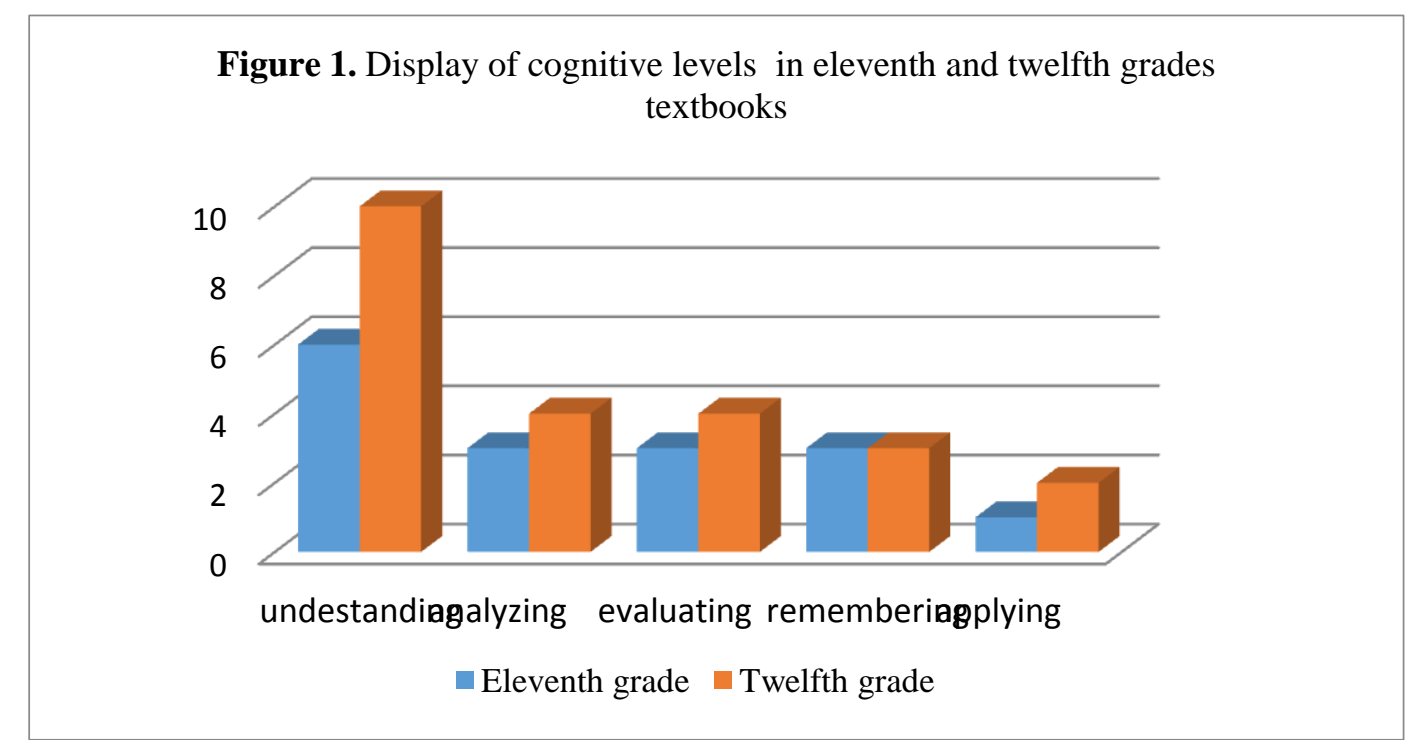

Table 2 shows the types of reading comprehension strategies for each grade level categorized according Bloom's revisited taxonomy of cognitive domains;

Table 2

Reading comprehension strategies according to Bloom's New Taxonomy of Cognitive Domain

Cognitive Ticket to English 1 Ticket to English 2

Domain

\section{Lower level}

\section{Remembering}

Understanding

Applying

\section{Higher-level}

Analyzing

- $\quad$ summarizing

- Listing items

- Taking notes

- Understanding and interpreting information

- Reading the gist

- Reading for word association

- Making connections
- Checking predictions

- Debating

- evaluating information
- recalling information

- Listing information

- Reading for the gist

- Read and scan

- Read and interpret

- making connections

- Solving

- Making inferences

- Surveying the text

- Distinguishing between main ideas and supporting details

- Making predictions

- Evaluating information 
In the pre-reading stage, more importance is given to predicting and guessing tasks that are meant to actively involve students in constructing and retrieving meaning from the text. This basic strategy engages learners in active thinking and enables them to generate ideas and solutions. There is also an overuse of brainstorming as a pre-reading strategy. One of the main benefits of brainstorming is the activation of readers' prior knowledge (Feather (2004). Furthermore, it is likely that through this strategy, readers become conscious concerning what they know about a given text's topic before they go on reading it.

The content analysis of reading texts also revealed that HOTS are promoted mainly through post reading activities in which learners are asked to respond critically to the reading texts. The skills identified comprise the following abilities: building arguments and providing concrete evidence, debating and negotiating ideas, and tolerating cultural differences.

\section{DISCUSSION}

The findings of the present study are in accordance with previous studies showing that EFL textbooks in Morocco provide a small range of activities that stimulate young learners to think creatively and develop career and life-skills (Elboubekri , 2013; Bouzid, 2016). Earlier studies indicated that EFL textbooks do not sensitize learners to critical issues of diversity, tolerance, and peaceful coexistence among different religions (Bouzid, 2016). Correspondingly, teaching English language in Moroccan schools fails to tap into critical thinking approach as a source to enhance intercultural communication competence (Elboubekri , 2013).

The examined textbooks do not help students to engage in a scaffolded learning experiences designed to move them up from lower knowledge levels to higher level thinking skills. There is not a smooth transition from lower order thinking skills to higher order thinking skills. Thinking skills are not well developed or distributed. Some skills have a high rate of frequency while others have a very low rate of frequency. Additionally, some of the questions do not satisfy higher achiever students who need challenging questions to promote their thinking abilities.

The results of the study also showed a total absence of metacognitive knowledge. Based on these findings, Ticket to English series do not effectively help learners become critical thinkers. The textbooks under study are criticized for taking a narrow view of comprehension assessment. Skills such as knowing word meaning, comprehending literal meaning, and recognizing mood and author intent make up a relatively small portion of what a reader can comprehend.

The limited space allotted to the teaching of HOTS does not provide sufficient practice for students to negotiate meaning, make connections between course content and prior knowledge, and develop interpretive competence. As such, the textbooks do not fully equip learners with tools that would assist them in identifying, analyzing and evaluating the credibility of the material being read.

\subsection{Implications and Recommendations}

Despite its obvious potential for the academic and professional development of students, there is still a significant gap to be bridged in higher order thinking 
instruction in Moroccan schools. This type of active learning still has a long way to go to be incorporated more systematically and explicitly in secondary classrooms. Moroccan students' prior learning habits and experiences are mostly reproductionoriented. This is usually ascribed to the restricted chances to question, explain, or evaluate the knowledge instructed in the classroom.

The findings do not match the overall guidelines for teaching reading drawn up in accordance with the principles which subscribe to the standards-based approach. The curricula and syllabus have been designed with the objective of enabling learners to think critically, creatively, analytically, and systematically. They also purport to lay special focus on activities that foster problem-solving and informed decision-making.

HOTS are not extensively developed or practiced during primary and secondary education. With the lengthy syllabus to cover, teachers often declare that they hardly ever have time to dedicate to the teaching of HOTS. Others place the blame on students' poor performance in English language and see it as an impediment to the development of the twenty first century skills. Added to this is the fact that textbooks have not been updated since 2007. Another important reason is that some teachers themselves lack preparation for teaching these skills. Finally, the busy teaching schedule often makes it difficult for teachers to prepare appropriate materials to teach HOTS, hence the need for updated textbooks that incorporate interactive tasks that promote higher level thinking.

Throughout professional career as a teacher of EFL in secondary schools, the researcher has constantly observed that many of students show lack of understanding of basic concepts of critical reading and thinking skills, and assume therefore a passive attitude towards their own learning. This is clearly evidenced in that many of them are baffled when asked to explain or justify their ideas and interpretations of a reading text. Most of their responses are based on a shallow understanding of problem solving strategies or critical thinking. Regrettably, these students leave high school unprepared for the college experience.

As today's world is constantly and rapidly changing, curriculum developers have to cater for the increasing demands of today's world of globalization and information technology. In Morocco, English textbooks require constant revisions in that they significantly mold the minds of learners. It is our duty as instructors to assist students to become able to study and learn more independently and solve problems on their own through designing activities that foster the development of the abilities to think critically and creatively. To attain this end, it is my contention that instruction of critical reading and higher level thinking skills should take place throughout elementary classrooms. Many teachers take it for granted that young learners will develop HOTS automatically as they grow older and become more knowledgeable through reading in school. However, this widely held view has been contested by various ELT researchers including Stauffer (1977) who is of the opinion that critical thinking must and can be taught to students. Schools are accountable for developing citizens who will have the ability to read and think critically.

Other educational experts stress the need for developing students' critical thinking in the early grades of schooling (Hickey, 1988; McMillan \& Gentile, 1988). 
Thistlethwaite (1990), for instance, strongly emphasizes that "focusing on critical reading should not wait until presumably lower level reading skills have been mastered" (p.586).The above mentioned quote implies the importance of providing guidance to achieve active and critical reading comprehension of difficult texts. Teachers need to enable students to critically examine any text using key strategies for close reading. (Bean \& Ericson, 1989). School instruction should guide students to gradually expand their range of competence, and adequately prepare students to take charge of their own learning.

We need students who think out-side the box. This can be attained enriching young learners' language learning through engaging them in real-world thinking tasks that lead up to the development of critical thinking skills. School curricula need to be reexamined as they tend to promote systematic, error-free learning correct answers, assimilation of facts, and teacher's assessment.

Textbooks should incorporate the twenty-first century skills in all the stages of reading comprehension so that learners will be exposed to these skills to optimize the retention of the targeted strategies. Reading texts should provide readers with a variety of real-world scenarios to help them construct meanings from multiple perspectives and contest ideas. The reasoning behind exposing readers to multiple points of view is to prompt them to think and rethink their own ideas and actions. This is largely believed to help students gradually achieve self-direction and develop the disposition to become open-minded, self-confident, prudent and truth-seekers (Facione, 1992). To become fluent and effective readers, students " must not only decode words automatically; they must also learn how to construct meaning and bring in their prior knowledge to interact with the text" (Facione, 1992, p. 32).

Struggling readers need direct and explicit instruction in comprehension strategies to improve their reading comprehension and to overcome difficulties in understanding texts (Graham \& Bellert, 2004). Current research shows that the more explicit the strategy instruction, the higher the likelihood that the learner will be better equipped to deal with the reading comprehension (Manset-Williamson \& Nelson, 2005). It follows then that the more students become accustomed to reading comprehension strategies, the less support they require from the teacher (Duke \& Pearson, 2002).

Learners should be exposed to a variety of challenging texts targeting stimulating issues. Texts should also relate to their own interest, age, and tap on their prior knowledge and experience. Learners need to steadily be led through instruction to achieve a variety of lifelong skills and competencies. Teachers should ensure that learner readers are cognitively involved in the text drawing on their background knowledge to construct their own meaning.

In order to strike a balance between lower-order questions and higher-order ones, it is suggested that multilevel questions should be devised and incorporated at the end of each reading passage. To become effective readers, students need to acquire a set of inferential and reasoning skills to make meaningful connections between information in the text and relevant background knowledge (Aloqaili, 2012). The activities presented in textbooks should proceed from simple to complex, from concrete to abstract and should follow a chronological order (Erten et al, 2015). 
Based on the results obtained from this study, the following recommendations can be drawn:

1. A survey to be administered to students and teachers is highly needed as it may uncover more valuable results on textbook evaluation.

2. English language teachers need to provide enrichment materials, with more exercises that cover higher order thinking skills.

3. English supervisors should conduct a series of workshops to train English teachers on how to develop and enhance students' thinking skills.

\section{CONCLUSION}

This paper attempted to evaluate the content of Moroccan ELT textbooks in terms of their inclusion of the skills that best meet the needs of the twenty-first century. It aimed to investigate the extent to which Ticket to English textbooks currently used in public high schools provide activities that help students develop the necessary skills needed for the 21 st century. This paper also suggested ways in which future textbooks could improve their content by including more activities targeting the teaching of HOTS. The findings obtained from the content analysis of both Ticket to English 1 and 2 revealed that they did not provide a sufficient number of activities that would help foster the higher order thinking skills among learners. Added to this is the dependence of the coursebooks on traditional activities that were meant to develop reading comprehension. The findings derived from this case study might be of some benefit to EFL curriculum designers as well language teachers to include appropriate tasks and activities that enhance learners' critical reading skill along with critical thinking ability.

\section{REFERENCES}

Almasi , Janice F \& Fullerton, Susan King. (2012). Teaching Strategic Processes in Reading. Guilford Press.

Anderson, L. W., et al. (2001). A Taxonomy for Learning, Teaching, and Assessing: A Revision of Bloom's Taxonomy of Educational Objectives. New York: Longman.

Arena, L.A. (2013). Language Proficiency: Defining, Teaching, and Testing. Springer Science \& Business Media,

Behjat, Fatemeh. (2013). An Adopted Framework to Evaluate ELT Supplementary Materials: The Applicability of "Top Notch" Software. Journal of Studies in Learning and Teaching English, Vol. 1, No. 3, 1-13

Bouzid, Hassan Ait. (2016a). Promoting Values of Religious Tolerance through Moroccan ELT Textbooks. ASIAN TEFL, 1(2), 2016. http://www.asiantefl.com/

Bouzid, Hassan Ait. (2016b). Boosting $21^{\text {st }}$ Century Skills through Moroccan ELT Textbooks. JELTL (Journal of English Language Teaching and Linguistics), 1(2), 2016.

DOI: http://dx.doi.org/10.21462/jeltl.v1i2.24. http://jeltl.org/ 
Chen, Mei-Hui. (2016). Theoretical Framework for Integrating Higher-order Thinking into L2 Speaking, ISSN 1799-2591. Theory and Practice in Language Studies, Vol. 6, No. 2, pp. 217-226, DOI: http://dx.doi.org/10.17507/tpls.0602.01

Cole, Bronwyn \& McGuire, Margit. (2012). Real-World Problems: Engaging Young Learners in Critical Thinking, competence. Social Studies and the Young Learner : National Council for the Social Studies, 24 (4), pp. 15-17

Cruz, E. (2003). Bloom's revised taxonomy. In B. Hoffman (Ed.), Encyclopedia of Educational Technology. Retrieved July 23, 2009, from http://coe.sdsu.edu/eet/Articles/bloomrev/start.htm

Cunnings worth, A. (1995). Choosing your Coursebook. London: Macmillan: Heinemann.

David R. Krathwohl (2002): A Revision of Bloom's Taxonomy: An Overview, Theory Into Practice, 41:4, 212-218.

Elboubekri, A. (2013). Multilingual education in Morocco and the question of cultural identity: Toward implementing a critical thinking approach in high school English textbooks. Academic Journals, 8 (20) DOI: 10.5897/ERR2013.1576

Erten, Sinan, Şen Ceylan, Yüzüak \& Ahmet Volkan. (2015). A Critical Analysis to 5th Grade Elementary Science education Textbook. International Journal of Humanities Social Sciences and Education (IJHSSE) Volume 2, Issue 1, PP 60-65, www.arcjournals.org

Flynn, L. L. (1989). Developing critical reading skills through cooperative problem. International Literacy Association. Vol. 42, No. 9, pp. 664-66

Harmer, J. (2001). The Practice of English Language Teaching. Essex: Pearson Education

I.G. Kennedy et al. (2016). Education Skills for 21st Century Teachers : Voices From a Global Online Educators' Forum. Journal of Adolescent \& Adult Literacy. DOI ISSN 1799-2591 Volume 6, Number 2

Kim, D.J. \& Hall, J.K. (2002) The role of an interactive book reading program in the development of L2 pragmatic competence, The Modern Language Journal, $86,332-348$

Krippendorff, K. (2013). Content analysis: An introduction to its methodology. CA: SAGE Publications, Inc.

Laabidi, H. (2016). Fundamental criteria for effective textbook evaluation. EFL Journal, 1 ( 2) doi: http://dx.doi.org/10.21462/eflj.v1i2.13.

L. Carrell, Patricia; Devine ,Joanne \& E. Eskey, David. (1988). Interactive Approaches to Second Language Reading, Cambridge University Press.

L. Sheldon (1988). Evaluating ELT Textbooks and Materials. ELT Journal, 42(4), 237-246.)

Marier, R. (2000). Reading Comprehension Techniques for Improving Students' Success in Extracting Useful Knowledge from Text. New Jersey: Pearson Education, Inc. 
Masuhara, Hitomi, Mishan, Freda, \& Tomlinson, Brian. (2017). Practice and Theory for Materials Development in L2 Learning. Cambridge Scholars Publishing.

McDade, S. A. (1995). Case Study Pedagogy to Advance Critical Thinking. Teaching Psychology, 22 (1), 9-10

McDavitt, D. S. (1993). Teaching for Understanding: Attaining Higher Order Learning and Increasing Achievement through Experimental Instruction. Unpublished Thesis. Retrieved from: http://www.eric.ed.gov

Nunan, D. (1988). Syllabus Design. Oxford: O.U.P.

Paul, R., \& Elder, L. (2009). Close reading, substantive writing, and critical thinking: foundational skills essential to the educated mind. Gifted Education.

Pescatore, C. (2007). Current events as empowering literacy: For English and social studies teachers. Journal of Adolescent and Adult Literacy, 51(4), 326-339.

Petress, K. (2005). Questions and Answers: The Substance of Knowledge and Relationship. College Student Journal,374-376.

Rauch, s. j. et al,. (1968). Mastering Reading Skills. New York: D.van Nostrand Company.

Richards, J.C. (2001). Curriculum Development in Language Teaching. Cambridge:

Cambridge University Press.

Krathwohl, D. R. (2002). A revision of Bloom's taxonomy: An overview. Theory into Practice, 41(4), 212-218. Retrieved from Marksberry, M., (1963). Foundations of creativity. New York: Harper \& Row Publishers.

Schneider, Vera. (2002). Critical thinking in the elementary classroom: Problems and Solutions. Educators publishing service

Spolsky, Bernard \&Sung, Kiwan. (2015). Secondary School English Education in Asia From Policy to Practice. Routledge.

Staufer, R. (1977). Directing the Reading-thinking process. New York: Harper and Row.

Subekti, A.S. (2017). The Use of a Commercial Textbook in English 1 Course at a University in South Korea. IJELTAL (Indonesian Journal of English Language Teaching and Applied Linguistics), 1(2), 2017

Tomlinson, B. et al. (2001). ELT Courses for Adults. ELT Journal, 55(1) 80-101.

Weir, C. J. \& Roberts, J. (1994) Evaluation in ELT. Oxford: Blackwell.

Williams, E. (1996). Reading in the Language Classroom. Malaysia: Modern English Publications.

Wright, I. (2002). Is That right? Critical Thinking and the Social World of the Young Learner. Toronto: Pippin Publishing Corporation. 